\title{
Flame Spray Synthesis and Ammonia Sensing Properties of Pure $\alpha-\mathrm{MoO}_{3}$ Nanosheets
}

\author{
Gagan Jodhani, Jiahao Huang, and Perena Gouma \\ Department of Materials Science and Chemical Engineering, Stony Brook University, 100 Nicolls Road, \\ Stony Brook, NY 11794, USA \\ Correspondence should be addressed to Perena Gouma; pelagia.gouma@uta.edu
}

Received 30 June 2016; Accepted 8 November 2016

Academic Editor: Carlos R. Cabrera

Copyright (C) 2016 Gagan Jodhani et al. This is an open access article distributed under the Creative Commons Attribution License, which permits unrestricted use, distribution, and reproduction in any medium, provided the original work is properly cited.

\begin{abstract}
This paper highlights the flame spray synthesis of $\alpha-\mathrm{MoO}_{3}$ using ammonium molybdate as precursor. The as-synthesized particles obtained were found to be ammonium molybdenum oxide and belonged to the triclinic crystal system. The particles crystallized to $\alpha-\mathrm{MoO}_{3}$ upon thermal treatment at $500^{\circ} \mathrm{C}$. Sensors were prepared by drop coating the powders onto alumina substrates coated with platinum electrodes and sensing tests were conducted evaluating the detection of ammonia concentrations down to ppb level concentration in air. The flame synthesized $\alpha-\mathrm{MoO}_{3}$ based sensors show high sensitivity towards ammonia and may potentially be used in breath ammonia gas diagnostics.
\end{abstract}

\section{Introduction}

The orthorhombic phase of $\mathrm{MoO}_{3}$, commonly known as $\alpha$ $\mathrm{MoO}_{3}$, has been used for variety of applications in gas sensing of ammonia [1,2], Li-ion intercalation in batteries [3-5], pseudocapacitors [6-8], and hydrogen absorption [9]. Recent studies have led to development of $\alpha-\mathrm{MoO}_{3}$-polymer composite electrodes with a greatly improved cycling behavior for use in aqueous lithium [10] and sodium [11] rechargeable batteries. The layered structure of the material consists of $\mathrm{MoO}_{6}$ octahedra held together by Van der Waals forces. The layered structure and the ease of $\mathrm{Mo}(\mathrm{VI}) / \mathrm{Mo}(\mathrm{V})$ coupling enable $\mathrm{MoO}_{3}$ to be of interest in electrochemical systems [12]. For gas sensing, this polymorph has shown high specificity to detecting ammonia gas through a reaction process involving the reduction of the oxide $[13,14]$.

$\alpha-\mathrm{MoO}_{3}$ was synthesized by our research group through various different routes (sol-gel process, sputtering, electron beam deposition, electrospinning, etc. $[2,13,15])$. Also it was studied in diverse configurations (nanoparticles and nanowires $[2,13])$. However, in order to be able to manufacture ammonia sensors based on nanostructured $\alpha-\mathrm{MoO}_{3}$ in large quantities, a scalable nanomanufacturing process needs to be used for the materials synthesis. Flame spray pyrolysis is such a process, and it is explored here for the synthesis of $\mathrm{MoO}_{3}$. The methodology used to produce particles at a laboratory based FSP setup can be transferred to a foundry for bulk synthesis of the material. Aeroxide P25 Titania from Evonik Industries is an example of commercial Titania nanopowder synthesized via flame aerosol technique. Apart from the commercial aspect, the advantage of flame spray synthesis lies in ease of fabrication, elimination for the use of expensive raw materials, uniform size distribution, and high purity of product. Flame synthesized particles offer small particle size along with high surface-area-to-volume ratios; these characteristics make them desirable for gas sensing and electrochemical applications.

Earlier synthesis by other workers of $\mathrm{MoO}_{3}$ via flame spray pyrolysis relied on $\mathrm{TiO}_{2}$ doping to stabilize the $\alpha$ phase [16]. However, doping agents tend to create long-term stability issues in sensing materials [17] and thus pure $\alpha$ $\mathrm{MoO}_{3}$ is the desirable product of FSP processing.

\section{Experimental Method}

$\mathrm{MoO}_{3}$ particles were synthesized via flame spray pyrolysis (Tethis nps 10) technique. A $0.68 \mathrm{M}$ solution of ammonium 


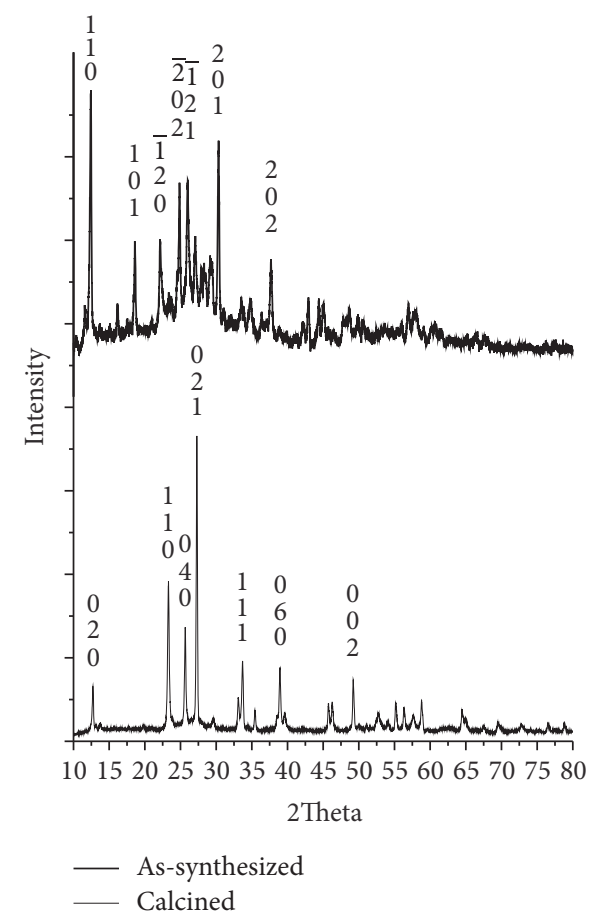

(a)

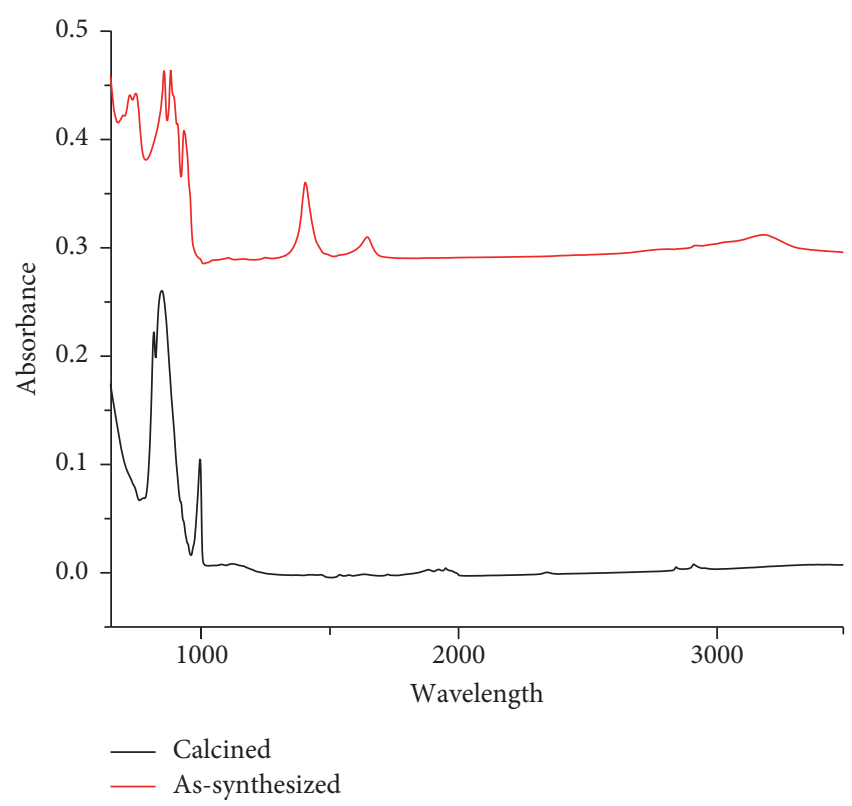

(b)

FIGURE 1: (a) XRD pattern on as-synthesized and calcined $\mathrm{MoO}_{3}$ powders. (b) FTIR pattern on as-synthesized and calcined $\mathrm{MoO}$, powders.

molybdate tetrahydrate (Sigma-Aldrich 277908) was prepared in a mixture of distilled water and dimethylformamide in a ratio of $5: 1$, respectively. The solution was vigorously stirred to obtain a homogenous mixture. The solution was then filled in a syringe and fed into the FSP system at a rate of $5 \mathrm{~mL} / \mathrm{min}$. The flame was comprised of $1.5 \mathrm{slm}$ (standard liters per minute) methane and $3.0 \mathrm{slm}$ oxygen gas. A $5 \mathrm{slm}$ oxygen gas flow was used as dispersion gas. The particles obtained after FSP process (as-synthesized particles) were black in color; upon thermal treatment at $500^{\circ} \mathrm{C}$ for 5 hours, the color of the particles changed to white (calcined).

The powders were characterized using Scanning Electron Microscopy (SEM, LEO 1550) and Transmission Electron Microscopy (TEM, JEOL 1400) and selected area electron diffraction was carried out on both as-synthesized and calcined samples. Thermogravimetric analysis (TGA, Perkin Elmer Diamond) was conducted on the as-synthesized samples. The particles, both as-synthesized and calcined, were also characterized using XRD (Rigaku MiniFlex II) and FTIR (Thermo Scientific Nicolet 6700).

For sensing experiments, sensors were prepared by drop coating a slurry of as-synthesized particles in ethanol on sensor substrates. The sensors were then thermally treated at $500^{\circ} \mathrm{C}$ for $5 \mathrm{~h}$. Sensing data was collected using a gas flow bench and multimeter. A stable baseline was obtained for the sensors in extra dry air; $485^{\circ} \mathrm{C}$ was used as the operating temperature. Sensing data was collected for ammonia in the concentration of $4,2.5,1$, and $0.5 \mathrm{ppm}$.

\section{Results and Discussion}

3.1. Phase Characterization and Thermal Stability. XRD data for powders before and after thermal treatment was obtained (Figure 1(a)). The XRD pattern obtained for as-synthesized powders coincides with JCPDS file 80-0757, which is for triclinic ammonium molybdenum oxide $\left(\mathrm{NH}_{4}\right)_{2}\left(\mathrm{Mo}_{4} \mathrm{O}_{13}\right)$. The formation of compound can be attributed to the flame degradation of precursor, ammonium molybdate tetrahydrate, and entrapment of ammonia and water vapors inside the powders during particle formation. In case of XRD for powders upon calcination the peaks observed coincide with JCPDS file 05-508, which is for $\alpha-\mathrm{MoO}_{3}$. The FTIR analysis of the powders is shown in Figure 1. In case of the FTIR spectrum for as-synthesized powders, peaks are noticed at $840,850,980,1400,1640$, and $3140 \mathrm{~cm}^{-1}$. The peaks at 3140 and $1640 \mathrm{~cm}^{-1}$ can be attributed to water as per NIST database [18]; the peaks at 840 and $980 \mathrm{~cm}^{-1}$ relate to $\mathrm{N}-\mathrm{H}$ bonds and inclusion of $\mathrm{NH}_{3}$ in the sample [18]. Only one peak found at $850 \mathrm{~cm}^{-1}$ relates to the Mo-O-Mo [19]. For powders received upon thermal treatment, peaks were noticed at 818 , 850 , and $999 \mathrm{~cm}^{-1}$. The strong peak at 850 and the weak peak at $818 \mathrm{~cm}^{-1}$ are a result of Mo-O-Mo bond, with the weak peak being a resultant of asymmetric molybdenum stretching [19]. The strong peak at $999 \mathrm{~cm}^{-1}$ is a result of $\mathrm{Mo}=\mathrm{O}[19,20]$, which indicates a layered structure. No peaks were obtained for water, indicating that the water molecules included in the precursor were decomposed during processing. 


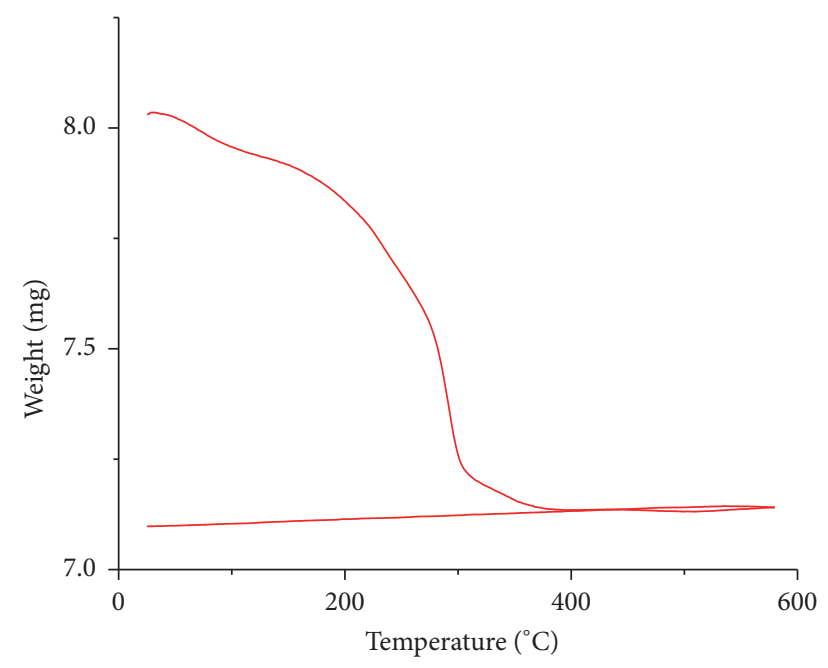

FIGURE 2: TGA analysis of as-synthesized powders.

Thermogravimetric analysis was performed on the assynthesized powders from room temperature to $580^{\circ} \mathrm{C}$ under oxygen atmosphere. Figure 2 shows the effect of temperature on the powders. A sharp drop in the weight is noticed at $325^{\circ} \mathrm{C}$, indicating the decomposition of ammonium salt and formation of $\alpha-\mathrm{MoO}_{3}$. The decomposition temperature for $\left(\mathrm{NH}_{4}\right)_{2}\left(\mathrm{Mo}_{4} \mathrm{O}_{13}\right)$ was found to be in accordance with the literature [21], where an endothermic reaction was reported at $317^{\circ} \mathrm{C} ; \mathrm{NH}_{3}$ and $\mathrm{H}_{2} \mathrm{O}$ were the decomposition products and $\alpha-\mathrm{MoO}_{3}$ was reported as the final product. No change was noticed upon further increasing the temperature to $550^{\circ} \mathrm{C}$ or during the cooling process indicating formation of a thermally stable phase.

3.2. Particle Morphology. Figure 3 shows the Scanning Electron Micrographs obtained for as-received (Figures 3(a) and 3(b)) and calcined (Figure 3(c)) $\mathrm{MoO}_{3}$ powders. Metal oxides in the form of nanorods (20-40 $\mathrm{nm}$ diameter covering spheres $(\sim 1 \mu \mathrm{m}$ diameter $)$ ) were observed for the as-received powders. Since the morphology of $\alpha-\mathrm{MoO}_{3}$ is usually in the form of nanorods/nanosheets/nanoribbons, due to its layered structure, the nanorods found on spherical particles of as-synthesized material were characterized using TEM and SAED (Figure 3(d)). The nanorods were found to be amorphous; SAED pattern picked up signals from lowly crystalline particles in the background. However, no evidence was found for the existence of $\alpha-\mathrm{MoO}_{3}$ in as-synthesized samples. The micron sized particles, which were spherical in nature, were of ammonium molybdenum oxide and a product of the FSP synthesis.

For the calcined powders, the morphology observed was nanosheets with thicknesses in the range of 20-40 nm, width in the range of $700-800 \mathrm{~nm}$, and length in the range of $1-1.5 \mu \mathrm{m}$. Such morphology was reported earlier for flame synthesized $\mathrm{MoO}_{3}$ in doped form [16] and by our group for $\mathrm{MoO}_{3}$ obtained after thermal degradation of electrospun mats [2]. The formation of the nanosheets is due to the low energy configuration for $\alpha-\mathrm{MoO}_{3}$ particles. The thermodynamically stable form consists of 2 similar chains of $\mathrm{MoO}_{6}$ octahedra aligned in $a b$ configuration [22]. The as-synthesized particles reported here are bigger compared to those reported earlier due to higher concentration of precursor (increased agglomeration in chamber) and lower flame temperature (incomplete evaporation of particles).

3.3. Ammonia Sensing. The calcined $\mathrm{MoO}_{3}$ particles were tested as ammonia sensor operated at $485^{\circ} \mathrm{C}$ in extra dry air and ammonia in the concentration (denoted by $C$ on graphs) of $4 \mathrm{ppm}, 2.5 \mathrm{ppm}, 1 \mathrm{ppm}$, and $0.5 \mathrm{ppm}$. The sensors showed fast response time of 40 seconds. The sensing data is plotted against time, as can be seen in Figure $4(\mathrm{a}) ; R(y 1$ axis) versus time represents the change in resistance when a signal of ammonia was introduced; $C$ ( $y 2$ axis) versus time represents the times when a 3-second pulse of ammonia was introduced. The sensors were found to show high sensitivity; the sensitivity of the sensors at different concentrations of ammonia is shown in Figure 4(b).

The sensors showed a fast response to ammonia, with a strong drop in resistance, even at low concentration. Most of the earlier reported $\mathrm{MoO}_{3}$ based ammonia sensors have been shown to detect $10 \mathrm{ppm}$ or higher concentrations of ammonia. Gouma et al. [15] have been able to detect concentrations of ammonia down to $50 \mathrm{ppb}$ using spin coated $\mathrm{MoO}_{3}$ synthesized through sol-gel process. The current flame synthesized sensor was not tested for such low concentration, however, when the two sensors are compared for their sensitivity for $1 \mathrm{ppm}$ of ammonia; the flame synthesized sensors show a slightly better sensitivity (0.2) compared to spin coated ones (0.14). The sol-gel derived sensor showed a sensitivity of 0.012 at $50 \mathrm{ppb}$ concentrations; the FSP sensor, although not tested for low ammonia concentration, can be expected to perform at the same level as the sol-gel derived sensor. The comparable performance of the FSP derived sensor to sol-gel opens the path for commercial synthesis of the sensors for breath diagnostics. In their current form, the flame synthesized sensors show a sensitivity of .05 at $500 \mathrm{ppb}$ range and serve as better sensors in automotive applications [23].

\section{Conclusion}

Our study successfully demonstrates the synthesis of pure undoped $\alpha-\mathrm{MoO}_{3}$ through flame spray pyrolysis process. The sensors obtained show fast response and recovery times, good sensing resolution, and high sensitivity at low concentrations of ammonia. Moreover, the sensing results were found to be comparable to sol-gel derived sensor developed for breath diagnostics. Hence, the synthesis method opens the pathway for commercial synthesis of $\alpha-\mathrm{MoO}_{3}$ sensors for breath diagnostics.

\section{Competing Interests}

The authors state that there are no competing interests regarding the publication of this paper. 


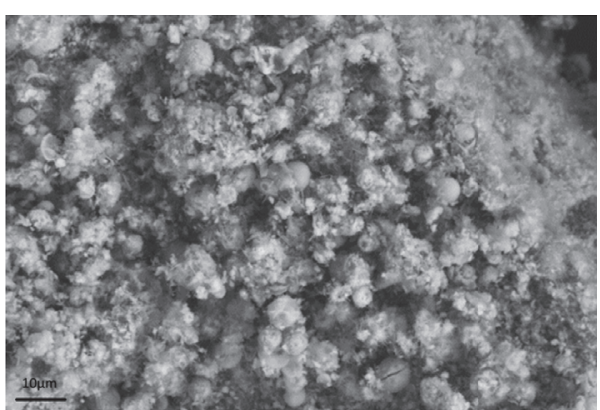

(a)

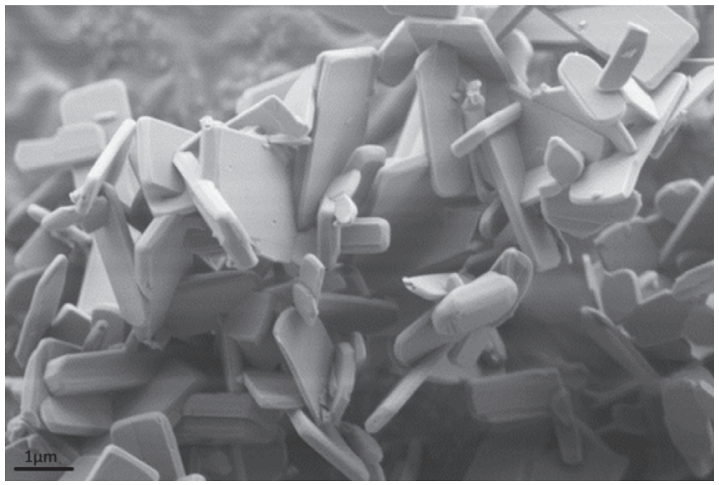

(c)

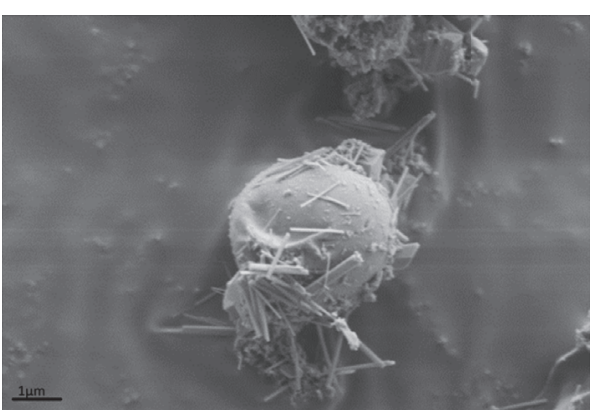

(b)

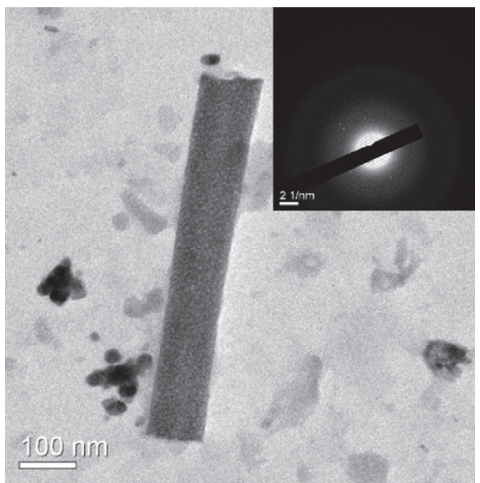

(d)

Figure 3: Scanning Electron Micrographs of (a) as-synthesized molybdenum particles. (b) High magnification image of as-synthesized molybdenum particles. (c) Molybdenum particles after thermal treatment. (d) TEM image of nanorods in as-synthesized samples.

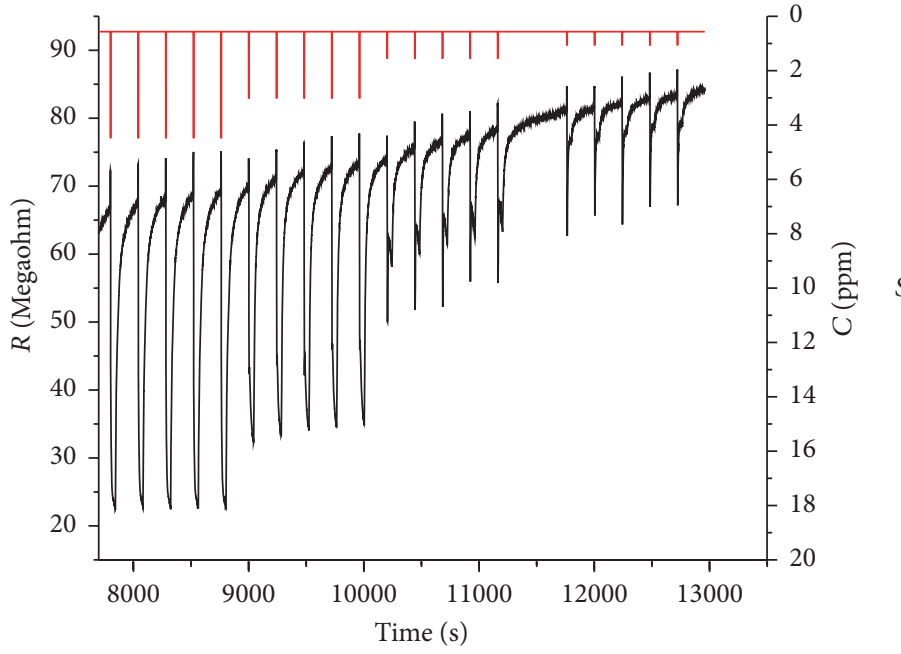

C

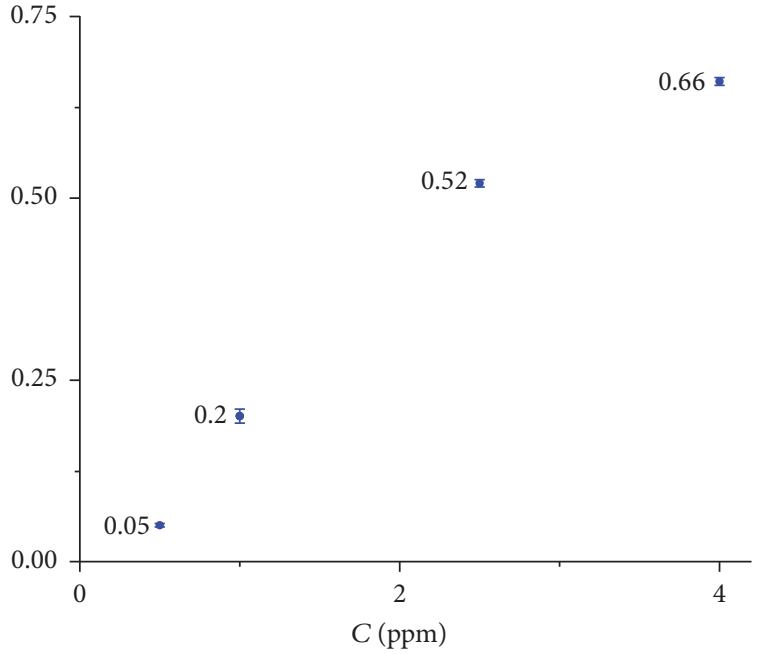

(b)

Figure 4: (a) Sensing data for ammonia at $485^{\circ} \mathrm{C}$. (b) Sensitivity plot for ammonia. 


\section{Acknowledgments}

This project was sponsored by National Science Foundation DMR no. 1106168. Research was carried out in part at the Center for Functional Nanomaterials, Brookhaven National Laboratory, which is supported by the US Department of Energy, Office of Basic Energy Sciences, under Contract no. DE-SC0012704.

\section{References}

[1] K. M. Sawicka, A. K. Prasad, and P. I. Gouma, "Metal oxide nanowires for use in chemical sensing applications," Sensor Letters, vol. 3, no. 1, pp. 31-35, 2005.

[2] P. Gouma, K. Kalyanasundaram, and A. Bishop, "Electrospun single-crystal $\mathrm{MoO}_{3}$ nanowires for biochemistry sensing probes," Journal of Materials Research, vol. 21, no. 11, pp. 29042910, 2006.

[3] K. Dewangan, N. N. Sinha, P. K. Sharma, A. C. Pandey, N. Munichandraiah, and N. S. Gajbhiye, "Synthesis and characterization of single-crystalline $\alpha$-MoO3 nanofibers for enhanced Li-ion intercalation applications," CrystEngComm, vol. 13, no. 3, pp. 927-933, 2011.

[4] Y. Iriyama, T. Abe, M. Inaba, and Z. Ogumi, “Transmission electron microscopy (TEM) analysis of two-phase reaction in electrochemical lithium insertion within $\alpha-\mathrm{MoO}_{3}$," Solid State Ionics, vol. 135, no. 1-4, pp. 95-100, 2000.

[5] L. Zhou, L. Yang, P. Yuan, J. Zou, Y. Wu, and C. Yu, “ $\alpha-\mathrm{MoO} 3$ nanobelts: a high performance cathode material for lithium ion batteries," Journal of Physical Chemistry C, vol. 114, no. 49, pp. 21868-21872, 2010.

[6] T. Brezesinski, J. Wang, S. H. Tolbert, and B. Dunn, "Ordered mesoporous $\alpha-\mathrm{MoO}_{3}$ with iso-oriented nanocrystalline walls for thin-film pseudocapacitors," Nature Materials, vol. 9, no. 2, pp. 146-151, 2010.

[7] R. Liang, H. Cao, and D. Qian, " $\mathrm{MoO}_{3}$ nanowires as electrochemical pseudocapacitor materials," Chemical Communications, vol. 47, no. 37, pp. 10305-10307, 2011.

[8] A. V. Murugan, A. K. Viswanath, C. S. Gopinath, and K. Vijayamohanan, "Highly efficient organic-inorganic poly(3,4ethylenedioxythiophene)- molybdenum trioxide nanocomposite electrodes for electrochemical supercapacitor," Journal of Applied Physics, vol. 100, no. 7, Article ID 074319, 2006.

[9] X. Sha, L. Chen, A. C. Cooper, G. P. Pez, and H. Cheng, "Hydrogen Absorption and Diffusion in Bulk $\alpha-\mathrm{MoO}_{3}$," Journal of Physical Chemistry C, vol. 113, no. 26, pp. 11399-11407, 2009.

[10] W. Tang, L. Liu, Y. Zhu, H. Sun, Y. Wu, and K. Zhu, "An aqueous rechargeable lithium battery of excellent rate capability based on a nanocomposite of $\mathrm{MoO}_{3}$ coated with $\mathrm{PPy}$ and $\mathrm{LiMn}_{2} \mathrm{O}_{4}$," Energy \& Environmental Science, vol. 5, no. 5, pp. 6909-6913, 2012.

[11] Y. Liu, B. H. Zhang, S. Y. Xiao, L. L. Liu, Z. B. Wen, and Y. P. Wu, "A nanocomposite of $\mathrm{MoO} 3$ coated with PPy as an anode material for aqueous sodium rechargeable batteries with excellent electrochemical performance," Electrochimica Acta, vol. 116, pp. 512-517, 2014.

[12] M. C. Rao, K. Ravindranadh, A. Kasturi, and M. S. Shekhawat, "Structural stoichiometry and phase transitions of $\mathrm{MoO}_{3}$ thin films for solid state microbatteries," Research Journal of Recent Sciences, vol. 2, no. 4, pp. 67-73, 2013.
[13] A. K. Prasad, D. J. Kubinski, and P. I. Gouma, "Comparison of sol-gel and ion beam deposited $\mathrm{MoO} 3$ thin film gas sensors for selective ammonia detection," Sensors and Actuators B: Chemical, vol. 93, no. 1-3, pp. 25-30, 2003.

[14] A. K. Prasad, P. I. Gouma, D. J. Kubinski, J. H. Visser, R. E. Soltis, and P. J. Schmitz, "Reactively sputtered $\mathrm{MoO}_{3}$ films for ammonia sensing," Thin Solid Films, vol. 436, no. 1, pp. 46-51, 2003.

[15] P. Gouma, K. Kalyanasundaram, X. Yun, M. Stanaćević, and L. Wang, "Nanosensor and breath analyzer for ammonia detection in exhaled human breath," IEEE Sensors Journal, vol. 10, no. 1, pp. 49-53, 2010.

[16] G. D. Park, S. H. Choi, and Y. C. Kang, "Electrochemical properties of ultrafine $\mathrm{TiO}_{2}$-doped $\mathrm{MoO}_{3}$ nanoplates prepared by one-pot flame spray pyrolysis," RSC Advances, vol. 4, no. 33, pp. 17382-17386, 2014.

[17] G. Zhang and M. Liu, "Effect of particle size and dopant on properties of $\mathrm{SnO}_{2}$-based gas sensors," Sensors and Actuators, B: Chemical, vol. 69, no. 1-2, pp. 144-152, 2000.

[18] P. J. Linstrom and W. G. Mallard, NIST Chemistry WebBook, NIST Standard Reference Database Number 69, National Institute of Standards and Technology, Gaithersburg, Md, USA.

[19] R. K. Sharma and G. B. Reddy, "Synthesis and characterization of $\alpha-\mathrm{MoO}_{3}$ microspheres packed with nanoflakes," Journal of Physics D: Applied Physics, vol. 47, no. 6, Article ID 065305, 2014.

[20] C. V. Subba Reddy, Y. Y. Qi, W. Jin et al., "An electrochemical investigation on (MoO3+PVP+PVA) nanobelts for lithium batteries," Journal of Solid State Electrochemistry, vol. 11, no. 9, pp. 1239-1243, 2007.

[21] T. N. Kovács, D. Hunyadi, A. L. A. de Lucena, and I. M. Szilágyi, "Thermal decomposition of ammonium molybdates," Journal of Thermal Analysis and Calorimetry, vol. 124, no. 2, pp. 1013-1021, 2016.

[22] H. R. Oswald, J. R. Günter, and E. Dubler, “Topotactic decomposition and crystal structure of white molybdenum trioxidemonohydrate: prediction of structure by topotaxy," Journal of Solid State Chemistry, vol. 13, no. 4, pp. 330-338, 1975.

[23] P. I. Gouma, M. Stanacevic, and S. Simon, "An overview of the translation of selective semiconducting gas sensors from first results to automotive exhaust gas monitors to a platform for breath-based diagnostics," Translational Materials Research, vol. 2, no. 4, Article ID 045001, 2015. 

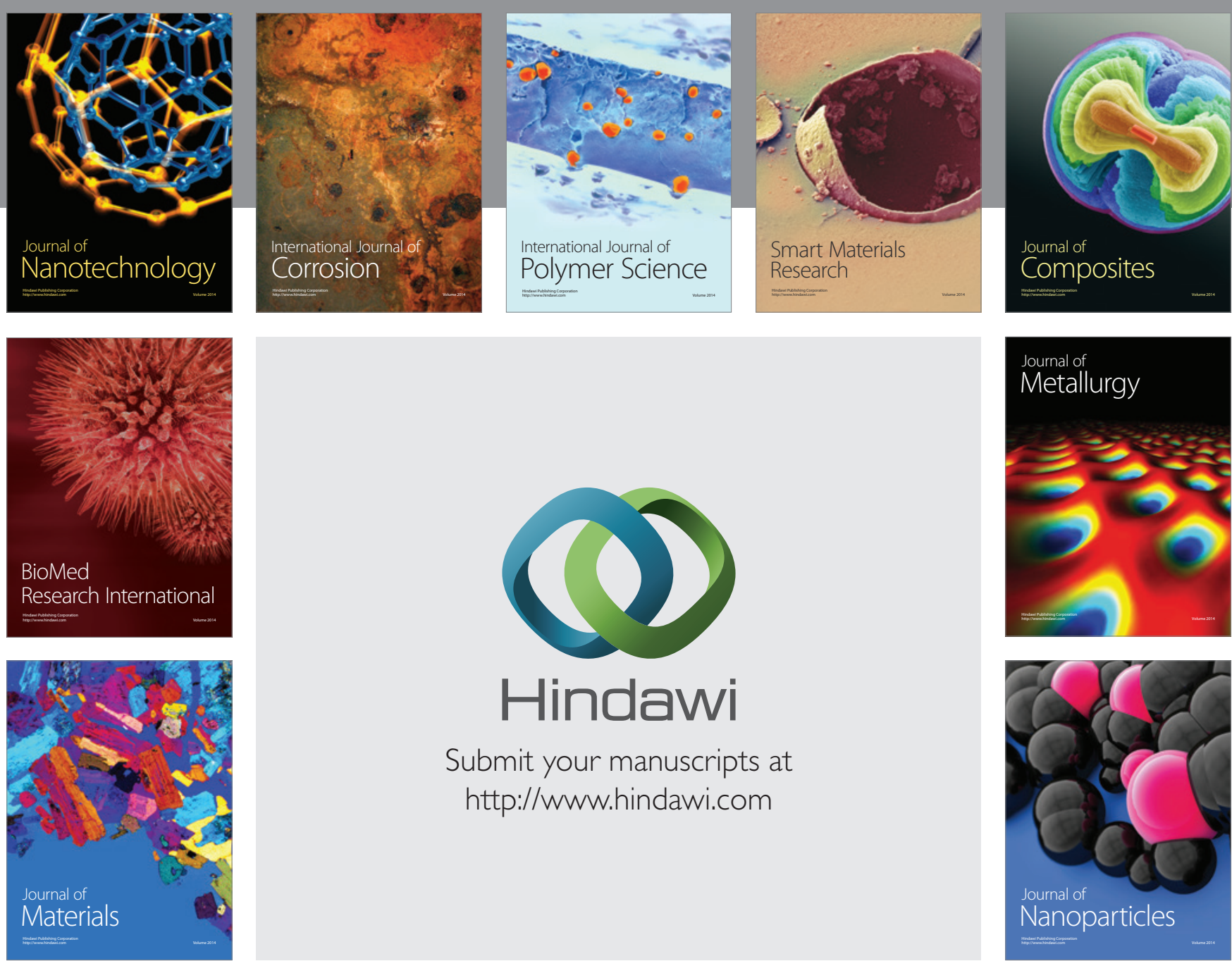

\section{Hindawi}

Submit your manuscripts at

http://www.hindawi.com

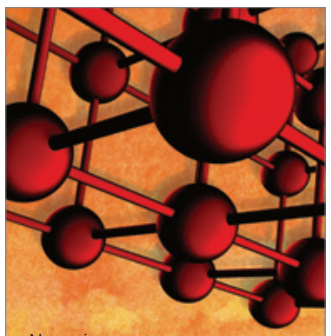

Materials Science and Engineering
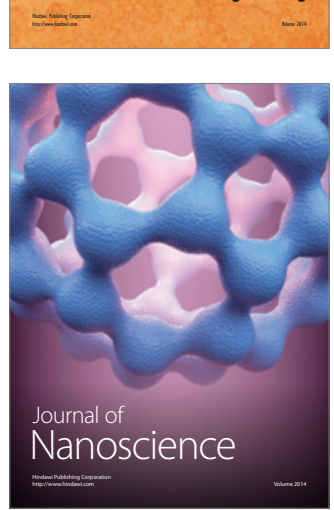
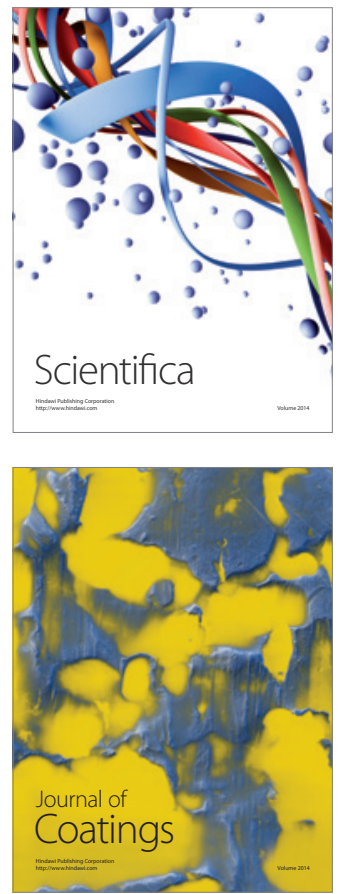
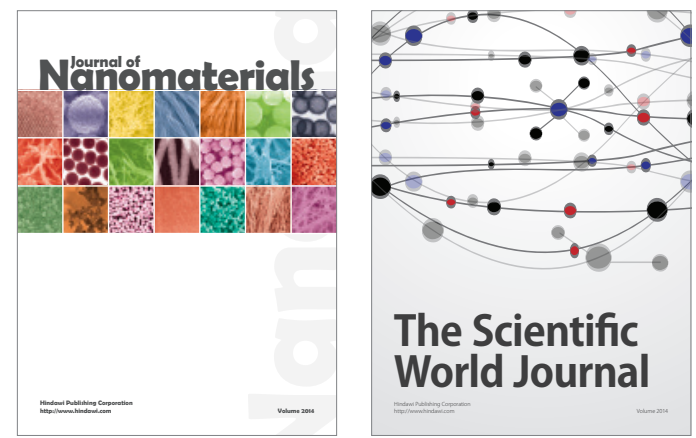

The Scientific World Journal
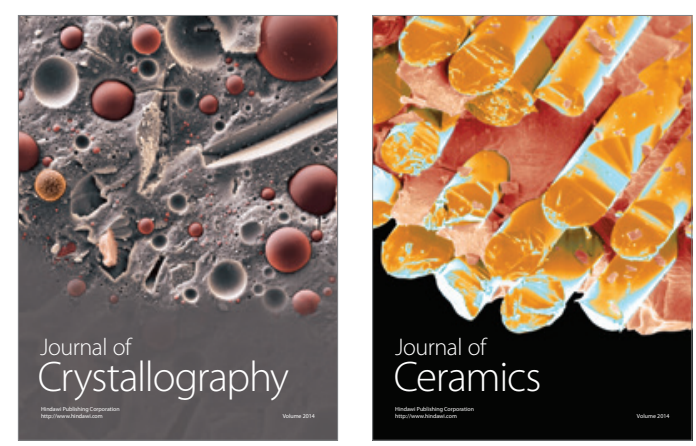
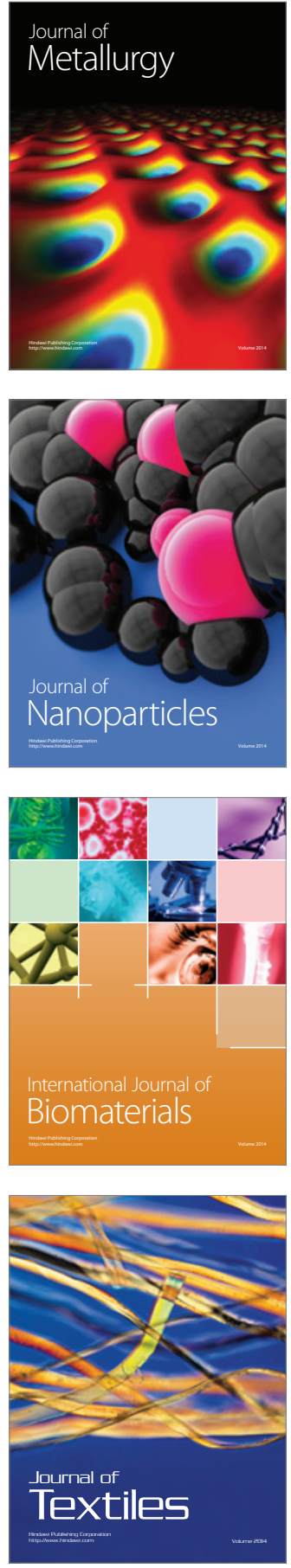